\title{
Contemporary issues of languaging, participation and ways-of-being
}

\author{
Sangeeta Bagga-Gupta \\ Professor of Education with a multidisciplinary background, School of \\ Language and Communication, Jönköping University, Jönköping, Sweden \\ sangeeta.bagga-gupta@ju.se
}

\begin{abstract}
This paper introduces the theme of Languaging, Diversity and Democracy. Contemporary issues of participation and ways-of-being and positions the 12 individual papers that constitute the 2022 double special issue of Bandung: Journal of the Global South. Its interest lies in contributing to knowledge that is relevant for contemporary human challenges related to issues of mobility, digitalization, and communication in and across different geopolitical regions across the planet and across virtual-physical spaces. Raising concerns regarding universalizing tendencies of special issues (and collected volumes generally), and based on the premise that what kind of knowledge matters is tied up with the issue of whose knowledge and in what named-language this knowledge matters, this paper raises critical queries that focus on the narrators positionality and gaze, the composition of scholarly narratives, the flow of narratives, what vocabularies circulate in frontline scholarship, including the organization of special issues, etc. Drawing attention to the universalizing Euro/America-centrism that shapes what counts as knowledge, the paper draws attention to the taken-for-grantedness of what counts as international languages of publishing which eclipses alternative epistemologies, waysof-thinking and ways-of-being. It argues that by taking such issues as inspiration in the curation and editing of this double special issue, participatory processes and ways-ofbeing enabled a contribution to the doing of democracy and diversity in the scholarly enterprise. Such work of democratizing academic publication work calls for unlearning to learn that is closely related to the theme explored in the double special issue. Aligning with analogue-digital languaging in contemporary existence, the paper also traces the journey of how this double special issue has come into being.
\end{abstract}




\section{Keywords}

democracy - languaging - participation - ways-of-being - academic publishing publishing regimes - digitalization - multiversal - researcher positionality unlearning to learn

\section{तत्त्व मीमांसा तत् त्वम् असि1}

You are looking at the introduction to the 2022 double special issue of the Bandung: Journal of the Global South (BJGS) on your digital screen, unless you have printed it and are reading it on tangible paper. Contemporary issues of languaging or communication, participation and ways-of-being in the scholarly world are mediated by the entanglements of digital-analog, screen-paper artefacts. Apart from the opening phrases, we can agree that the written languaging in this introduction is in the named-language ${ }^{2}$ English. The 12 papers that make up this double special issue are accessible in English, or rather different Englishes. Their abstracts are available in English and one other named-language. The authors of the 12 papers are situated across the planet and some variety of English constitutes one of the named-languages that they language in (at least in their academic work). Putting the spotlight on this communication or languaging and scholarly diversity is one way in which issues of democracy that frame academic publishing can be made explicit. Such explication implicitly highlights the lack of such scholarly diversity, including the continuing hegemonies of specific chosen English languaging in the scholarship. Such democratization endeavors are aligned with the increasing recognition being accorded to the need for going beyond the universalistic framings of northern

1 Notes related to these phases (in what is recognized as Sanskrit) are presented at the end of this paper.

2 Following theorizing on what language is, can be and whether it even exists (in particular, see Finnigan [2015] and the body of work by the integrationist scholar Roy Harris [2002, 2009], for some instances that shape my thinking on language and language research), I take the position that we have no choice but to call something - a behavior, an action - a "named" language. We demarcate this something from (an)other "named" language(s). While this labelling is inevitable, for the purposes of doing language or language related scholarship, "we should be clear that we are making them, that by going down one route we are excluding others, and - finally - that our decisions about what data counts may mean in effect tacitly lining up with some particular position about the nature and working of 'language"' (Finnegan 2015:14). 
epistemologies, ${ }^{3}$ including northern publishing regimes. ${ }^{4}$ In the context of this double special issue, we can ask what roles special issues play in contemporary academic existence given the increasing calls for multiversal framings? Do special issues cement niche or frontline areas and do they risk reproducing hegemonies, including publishing hegemonies in dominant written languaging? If so, how can special issues circumvent such risks? ${ }^{5}$

Many journals - in the social, human, and educational sciences at least offer openings for bringing together thematized special issues. Some make such dialogical spaces available routinely, others more sporadically. A niche area of expertise that is focused upon in a special issue (or an anthology) calls for contributions from scholars who have something (often new) to say in a given area. It is thus not uncommon that hand-picked scholars are invited to contribute; they are already active in a given (or emerging) frontline at a specific moment in time. ${ }^{6}$ Herein lies a risk of creating niche areas that follow a given epistemological or methodological trajectory, whereby alternative lines of thought become eclipsed. Multiversal thinking is thereby not on the agenda.

When a niche theme attempts to trouble the mainstream (for present purposes this can be framed as northern assumed ways of doing science globally) then the niche itself needs to open up to alternatives that cannot be fixed in advance. Highlighting that "[g]lobal hegemony grew out of imperial power", Connell suggests that criterion for such an enterprise lies in the "deep diversity" of higher education and research which engages "with a whole ecology of knowledge formations, not a monoculture" (2019: 177). The issue of what constitutes an alternative, or many different alternatives, is thus salient. In addition to a focus on the universalizing or multiversalizing theme being explored in a special issue, it becomes important to consider the following types of queries: who is doing the narrating, what vocabularies are being used, what is the composition of the narrative (i.e., the organization of a given paper and the organization of the special issue itself), what is the flow of the narrative (in individual papers and in the special issue), etc. As Lewis and Baderoon (2021)

3 See, for instance, Connell (2019, 2018), Deumert and Sinfree (forthcoming), Mufwene (2020), Rodríguez (2018), Santos (2018).

4 See, for instance, Collyer (2016), Connell (2019), Porsanger and Seurujärvi-Kari (2021).

5 Bagga-Gupta and Carneiro (2021) in a commentary to a recent special issue of the International Journal of Multilingualism offer illustrations regarding "nodal frontlines" in an attempt to go beyond singular universalizing linear imaginaries of niche areas in the scholarship (see also Connell 2019).

6 When these special collections claim to be "international", the complexity of a universalizing thinking, including (at best) a tokenizing presence of scholars from different geopolitical spaces, needs to be recognized and interrogated. 
highlight, "what kind of knowledge matters is linked to the question: Whose knowledge matters?" (p. 2, my emphasis).

Such questions relate to the fact that academic work in the social, human, and educational sciences is conceptual and as such builds on vagueness, and non-coherence as crucial dimensions of its framings: "variation is the order of all contexts" (Lincoln \& Guba 1985: 51; see also Bagga-Gupta \& Messina Dahlberg 2021). Far from viewing the human condition as knowable, clear or definite, its multiplicities, complexities and indeterminacies are in continuous need of remembrance in the epistemological enterprise (Santos 2018; Savransky 2017). Thus, engaging with unpredictability, perspectival and multiversal views needs to replace entrenched ideas regarding both objectivity and subjectivity: "Where we look from affects what we see. This means that any one focus of observation gives only a particular result... A whole picture is an image created morphogenetically from multiple perspectives" (Schwartz \& Ogilvy 1979:15). A path to dislodge mainstream ideas of doing science builds on, in Law's (2004) framing, a need for a "[d]isciplined lack of clarity" (3) to deal with the messy process of doing research, including writing research. Here communication (i.e., languaging) itself becomes a mobile trajectory resistant to singular universalizing clear mappings of research niche areas.

The universalizing Euro/America-centrism in what counts as knowledge is furthermore entangled with how academic writing and publishing regimes have been envisaged and framed (Collyer 2016; Heller \& McElhinny 2017; Santos 2018). Pragmatic concerns frame the fact that journals and other collections are published in a given named-language. To count as international, authors are required to language in one of the dominant European languages (these include English, German, Spanish, French and Portuguese). While this directly marginalizes scholars who are not socialized into these namedlanguages, the taken-for-grantedness of what counts as international languages of publication also - and more seriously - eclipses alternative epistemologies, ways-of-thinking and ways-of-being.

This double special issue whose introduction and 12 papers you have open access to, engages intellectually with the theme of Languaging, Diversity and Democracy. Contemporary issues of participation and ways-of-being (LaDD). In curating/editing it, my ambition has been to "walk-the-talk", i.e., make a concerted effort so that the collection illustrates the doing of democracy and diversity through participatory processes and ways-of-being in contemporary scholarship. Making the entire double special issue open access is one dimension of democratizing the scholarship. This has been enabled by resources 
from ongoing projects at the Communication, Culture and Diversity (CCD) research group (www.ju.se/ccd) ${ }^{7}$ at Jönköping University in Sweden.

With these as opening comments on languaging, diversity and democracy, I explicate the theme of the double special issue in the next section before turning attention to the diverse areas and topics covered in the 12 papers in this double special issue. After that I further unpack the work of democratizing academic publication work. The last section of this introduction aligns with languaging in contemporary existence through the journey of how this double special issue came into being.

\section{The Work of Communication in Contemporary Times}

there is, and long has been, a language myth deeply entrenched in Western culture ... that can be traced back over two millennia and more to the Classical period of ancient Greece. It is a myth of which we are all today - whether we regard ourselves personally as 'Western' or not - both beneficiaries and victims (HARRIS 20O2:1).

This collection has arisen from an interest in contributing to knowledge that is relevant for contemporary human challenges related to issues of mobility, digitalization, and communication in and across different geopolitical regions and across virtual-physical spaces. These challenges constitute prioritized areas (at least in democratically framed societies) during the last few decades. Issues of mobility, digitalization and communication are seen as being related to integration or inclusion and learning goals for all human beings across the lifespan more generally, and compulsory, higher and continuing education specifically. Furthermore, integration and inclusion have become critical agendas in contemporary societies in relation to recent demographic shifts related to mobility and digitalization more generally across the planet and in spaces that are conceptualized as the global-North more specifically. At the same time issues of equity and marginalization are increasingly confronted with rising

7 The Communication, Culture and Diversity research group was until 2016 located at Örebro University, Sweden and is situated since 2016 at the School of Education and Communication, Jönköping University in Sweden. I am grateful for this important support which enables access to scholarship irrespective of where on planet Earth a reader is located. 
right-wing agendas and a renaissance related to racism in a variety of ways across the planet.

In parallel, (some) scholarship that has emerged in the new millennium from the global-North has started recognizing the shaky nature of concepts like bi/multilingualism and diversity. ${ }^{8}$ This is evidenced, for instance, in the plethora of neologisms that have emerged with regards to key concepts like language ${ }^{9}$ and identity. ${ }^{10}$ Important emerging critique towards some of these newer "academic branded" concepts (Pavlenko 2019), however, draw attention to the nature of "normal-languaging" and "normal-diversity" (Bagga-Gupta \& Messina Dahlberg 2018, 2021; Machart, Clark \& Dervin 2014), including the need to recognize that what is being understood as new is perhaps newer ways of seeing, rather than a shift in communication repertoires (May 2014; Ndhlovu \& Makalela 2021). The intersections of languaging or the meaningmaking engagement of people where a range of semiotic resources are deployed - irrespective of the number of named-languages, language varieties, named-modalities, embodiment, or media deployed to communicate, and the performative dimensions of people's ways-of-being, rather than essentialized named-identity categories, constitute some dimensions of this emerging critique. Furthermore, while the neologism smorgasbord pertaining to language and identity has its origins in global-North spaces, recent concerns also point to the circulation of older and newer concepts related to language and identity into global-South spaces, wherein they continue to make invisible alternative epistemological and ontological conceptualizations (Bagga-Gupta 2021).

Demographic mobility and digitalization are thus understood as constituting significant contemporary issues related to language and identity (both inside and outside educational spaces) across the global-North/South. Furthermore, their complex nature calls for attending to them from multi/ cross/inter/transdisciplinary stances and in unison, rather than in terms of separate knowledge domains. The three key concepts of languaging, diversity and democracy that frame this double special issue are thus in need of being re-visited with the intention of being re-vitalized in relationship to what is being experienced in global-North spaces as new communicative practices where multiple named-language varieties, multiple named-language modalities and new technologies are involved. Furthermore, these concepts need to

8 And as mentioned earlier, the nature of language itself (see Finnegan 2015; Harris 2009, 2002).

9 For instance, translanguaging, translingualism, plurilanguaging, plurilingualism, metrolingualism, supervernaculars, etc.

10 For instance, superdiversity, hyperdiversity, newspeakerism, etc. 
be addressed by scholars from across the global-North/South with the intent of interrogating the continuing dichotomized situation (in many parts of the global-North) wherein monolingualism, monomodality and mono/essentialized named-identity constitutes the norm and specific understandings of multilingualism and diversity are seen as special, if not exotic.

\section{2 (Reflections on the) Twelve Contributions}

South and North are points on an ideological compass showing who have been underdogs in science and culture and who the self-proclaimed and self-perpetuating top dogs. (JOSEPH 2O21: XIII).

The theme LaDD - Languaging, Diversity and Democracy. Contemporary issues of participation and ways-of-being - is attended to in a diversity of ways by the authors of the 12 papers that make up this double special issue. The LaDD theme has not been a binding commitment for the authors in its strictest sense, even though each of the 12 papers engages with intersections of this tripodal theme in some unique manner. Building on the Sami concept of Lávvu ${ }^{11}$ and the Lávvu method (Posanger \& Seurujärvi-Kari 2021), I will suggest here that languaging, diversity and democracy function both as the three main poles of the Lávvu that has no central pole, and also the impetus for troubling taken-for-grantedness related to these three key concepts. So metaphorically, the Lávvu inspires us to understand this collection in terms of contributions that in a multitude of senses attempt to destabilize hegemonic ways of understanding languaging, diversity and democracy through re-thinkings of epistemology, ontology, and axiology.

My readings of these 12 contributions suggest that the authors engage with the tripodal concepts based on their historically shaped gazes and their mobility marked situatedness. This means that the theme (as spelt out in the call for papers) has hopefully functioned as a prompt, rather than a binding commitment for the authors. This is, in my view, a framing that allows the double special issue to function as a time-space collection that highlights how languaging in general and multilingualism in particular, diversity and democracy can be understood (at the beginning of the third decade of the 21st century) by scholars attempting to grapple with some pressing and intriguing issues of our

11 A sort of Tipi tent, the Lávvu is a temporary dwelling that builds on three poles that provide support to the structure, against which other poles and finally the tent surface is laid. The three key poles are not fixed with ropes and is highly stable even in harsh weather. 
times. It is the diverse localities and histories of each scholar (including each reviewer) who has participated in this enterprise that gives substance to what we can gleam in terms of the LaDD theme.

This collection brings together original empirically pushed and/or theoretically framed scholarship at the intersections of language, identity, and democracy from across the planet. The 12 contributions can be geographically pinpointed to where the authors are currently located (eight nation-states, half of which qualify formally as the global-South and the global-North each) or where the studies that they present focus on (nine regions and/or nation-states, seven of which formally qualify as the global-South). Furthermore, while seven studies can be understood as focusing on analog settings [including policy settings], five focus on digital settings or digital-analogue entangled contexts. In such intellectual explorations, the relevance of the taken-for-grantedness of the authors passports - present or previous - needs to be questioned. I will not indulge in the act of pin-pointing and cementing the authors dynamic mobilities, including digital-analogue lives, to places on the planet. ${ }^{12}$ The superficiality of such a task has become naturalized in our contemporary universalizing academic existence. Such fixations communicate hegemonies that need troubling. Suffice to say that the authors come from both the global-North and global-South, including the south in the north and the north in the south.

Each of the 12 papers has attempted to go beyond mono-disciplinary silos and indulge in a multi/cross/inter/transdisciplinary ethos in order to examine how issues related to languaging shape different individual and community ways-of-being and how these are related to democracy. Some papers do this more explicitly, others more implicitly. Walking-the-talk has meant that I have not called for the erasure of some concepts or the implementation of a new set of concepts that can trouble contemporary vocabularies and framings; such diversity in itself constitutes traces of multiversal thinking. Together the 12 papers contribute to creating a flow where it is the direction of the current that is of analytical interest, rather than the terminological meshwork that continues to be in need of disentanglement.

The 12 papers have not been grouped into themes or in geographical boxes - a choice I made to disturb the naturalized categories that are deployed for such work. The papers are presented in an ad hoc sequence. I briefly touch upon each paper here and point you, the reader, to the dual language abstracts that are available on the first page of each paper where you can create a personal idea before reading the papers. Paper 1 in this collection by Nii Kotei Nikoi

12 The interested reader can locate the authors to their contemporary localities by going to the first page of each paper or reading their short bios or searching digitally. 
and Seyram Avel is titled "In Between Hogging and Passing the Mic; Or, the Unintended Consequences of Networked Radio in Ghana". In addition to providing a rich account of the sociohistorical and contemporary socioscapes of the nation-state of Ghana, Paper 1 engages with the hybrid media spaces of English networked radio stations and argues that these spaces work as specific types of democratic arenas. Nii Kotei Nikoi and Seyram Avel discuss the media participation of active and passive citizens and issues of accountability that is enabled through these hybrid media spaces.

Maria Bäcke takes issue with omnipresent information and communication technologies across the nation-states of Sweden and India in Paper 2 that is titled "Resisting Commodification: Subverting the Power of the Global Tech Companies". Maria Bäcke calls attention to ethical dimensions of the easy access of technologies in schools and asks whether these technologies constitute a safe and sustainable solution. In addition to increasing awareness regarding the non-economic costs that different technologies bring with them, Paper 2 attempts to illuminate how those in power (sometimes) negotiate and subvert the inherent hierarchical hegemonies of global tech companies.

In Paper 3 titled "Diversity, Multilingualism and Democratic Practices in Nepal", Bhim Lal Gautam and Prem Prasad Poudel trouble the taken-forgrantedness of the relationship between democracy and the promotion and protection of linguistic diversity. Paper 3 provides reflections, illustrating that labels like linguistic diversity and multilingualism further political agendas primarily. It also discusses how policy can be mobilized to address micro problems for maintaining multilingualism within a democracy. Going beyond gaps between progressive policies and people's perceptions of their experiences, Sangeeta Bagga-Gupta in Paper 4 theorizes and highlights people's everyday lives in and across different digital-analogue settings. Titled "Promises IN policy' and 'policy AS participation': Equity and language in and across the wilderness of contemporary human life", Paper 4 argues for and illustrates the nature of complex processes that constitute policies of equity and language in terms of participation.

Miché Thompson in Paper 5, titled "Just enough English to get by: language practices of transnational migrants in Chinese stores in Cape Town, South Africa", focuses on multilingual workplaces in contemporary urban settings in the region of Western Cape. Miché Thompson unpacks the complex nature of human communication when participants do not always share linguistic resources. In Paper 6, titled "Service-Learning in the Ecuadorian Andes through Spanish, English and Kichwa Voicing", Veronica Yepez-Reyes and Karina A. Ortiz Pacheco draw attention to the cross-sectorial work that institutions of higher learning have access to through their engagements with local, regional, 
and cross-border communities. Paper 6 attempts to unpack the concept of service-learning and discusses intercultural communication through the authors work in the Andean paramo of Chugchilán. Augustin Lefebvre disturbs the categories of formal and informal education and adds to this typology by focusing on the glossed notion of second language learning in Paper 7 that is titled "Leader and follower: Towards the Organization for Economic Co-operation and Development's two interactional categories to describe learning situations?". Augustin Lefebvre focuses on the interactional organization of learning objects when the activity is teacher led in contrast with an activity that is learner led.

In Paper 8, titled "The Power of the Periphery. Circulation of cross-cultured languaging through the importation of Francophone comics in the nationstate of Sweden: 1900-2020", Ylva Lindberg focuses on global flows in the comic art market. Paper 8 tries to illustrate the democratization processes in the international literary field across time and challenges established hegemonies in the field. Paper 9 engages with four case studies from across time and space and presents a theoretical framework that Sangeeta Bagga-Gupta and Machunwangliu Kamei call a Second Wave of Southern Perspectives, SWaSP. Paper 9, titled "Liminality, Lim, Mobility and Memory. Disrupting the nature of things, beings and becomings", attempts to debunk the myths and imaginations that continue to give credibility to the idea of bounded language, fixed identity and boundary-marked nation-states, including the role of languaging as constitutive dimension of these processes. Chanel der Merwe, in Paper 10 titled "Re-considering orientations in South African language policies", confronts the question of what criteria are needed for developing language policies. Chanel der Merwe illustrates the need for universities to critically reflect on their own complicities in maintaining coloniality by asking whose knowledges, bodies, histories and lifeworlds they legitimize through policy work.

In Paper 11, titled "Sociolinguistic protests for decolonial future making: Toward centering languaging in the 'streets', Eunjeong Lee and Sinfree Makoni draw attention to the continuing perpetuation of hegemonic stances in the research on languaging, including a white-gaze understanding and approach to the term diversity. Eunjeong Lee and Sinfree Makoni offer the metaphor of streets as a way for scholars and the field to go beyond this hegemonic stance. In the final contribution in this double special issue, Anomitra Biswas and Tonisha Guin critically approach popular culture in a digital space by focusing on contemporary sites where taboo topics are explored. Paper 12, titled "Agents of Ishq and contemporary discourses on sex and sex-education in India", highlights the strengths of digital pedagogical resources and the concomitant need for problematizing cultural hegemonies that are embedded in the same. 


\section{$3 \quad$ Writing for What? Democratizing Academic Languaging in Contemporary Times}

I have started to think that I should stay there on the edge, not let myself get sucked in, retain that distance, because proximity to the frigid sun of the centre blinds more than it illuminates; that I should nurture, not flee, my marginality (SVALLFORS 2020: 56 ).

Bringing the diversity of topics and explorations spelled out in the previous section together into a special issue raises questions regarding editorial work, control, review scrutiny, etc. Issues pertaining to democratizing academic processes become salient against the backdrop of the fact that the LaDD theme itself calls for exploring issues of communication or languaging broadly, and the diversity of human existence, including the need for democratizing human existence. In addition to the cementing and hegemonizing risks of special issues I raised earlier in the opening section, I offer reflections here on some nitty-gritty issues related to some reasons why scholars write in contemporary times. Going beyond issues related to career advancements, scholarly written languaging is undertaken with the intent to communicate results, ideas and thinking with contemporary and future peers. Scholars also write to create communities of scholars explicitly or implicitly and/or communities of ideas.

Given the diverse intellectual, linguistic, geographical, and personal experiences scholars from across the planet bring with them, some rules of engagement are required. These rules of engagement are not natural framings but have become naturalized ways-of-being within publishing regimes. Editorial work in an international context, i.e., with a planetary diversity as backdrop, calls for reflecting on a range of contemporary issues that include ways of writing, ways of formulating ideas, ways of taken-for-grantedness in the contemporary academic publishing landscape (that includes definitions and naming of research areas and communicating these). Just raising issues concerning why scholars write and what rules of engagement are taken-for-granted in specific contexts becomes a key way to democratize the scholarship. Is contemporary writing (and publishing) undertaken primarily for communicating or is it undertaken primarily for creating communities (of authors focused on a special theme, for instance)? What pushes scholars to write, be critiqued, re-write... in the publishing (and conferencing) enterprise? These are far from innocuous queries. The Bandung: Journal of the Global South, (BJGS) journals framing raises important issues.

The opening paragraph of BJGs's author instructions draws attention to the need for alternative thinking: 
As a cross-disciplinary journal in the humanities and social sciences, Bandung: Journal of the Global South (BJGS) aims at providing an academic and policy platform for scholars and practitioners to develop new theoretical perspectives, share revealing findings, and exchange views. These should be grounded on the complex postcolonial landscapes of African, Asian, and Latin American peoples, for identifying their own ways and strategies of development and decolonization. Alternative paradigms, worldviews, ontologies, and epistemologies as well as praxis are encouraged to develop context-sensitive debates pertinent to African, Asian, and Latin American intellectual traditions and empirical, cultural, and theoretical realities.

Significantly, these opening words have been recently augmented with the following formulation:

Moreover, research perspectives from outside the Global South are welcome to facilitate the South-North dialogues (EMPHASIS ADDED).

Such framings take, as points of departure, a multiversal stance, rather than the hegemonic global-North taken-for-grantedness of a universal stance I raised at the beginning of this introduction. The new formulation in BJGs's author instructions is analytically significant and provides visibility to historical and contemporary mobilities, including our digital-analogue existence. It opens for acknowledging the fact that postcolonial, decolonial socioscapes exist in every corner of our spherical planet, including the complex entanglements of different regions of the world across time. This lies in line with the LaDD theme that cannot be curtailed to the "landscapes of African, Asian, and Latin American peoples". While encouraging alternative paradigms, worldviews, ontologies, epistemologies, and praxis are highly important in contemporary times, it is important to consider the underlying processes that are enabled and disabled given the languaging choices at hand for scholars from regions conventionally understood as the global-South. ${ }^{13}$ What rules of engagement exist implicitly and explicitly in the contemporary academic publishing sector? Explicit framings that are in place when it comes to the word-count, expectations regarding types of writing, including the language of publishing (as we have already seen), draw attention to global-North hegemonies that marginalize scholars

13 The call for abstracts for this special issue was made in English, and this choice itself both enabled and disabled participation from across the global-North/South, including the south in the north and the north in the south. 
from the "postcolonial landscapes of African, Asian, and Latin American" spaces. The note on language in BJGs's instructions for authors, draws attention to some further complexities of contemporary rules of engagement in the academic publishing landscape:

Manuscripts should be written in either British or American English. Spelling should be consistent throughout. The article title, abstract and keywords and the author name (if a name in another language is available, e.g. Arabic, Korean, Tamil and Thai) need to be provided in both English and another language. To facilitate international and trans-cultural communications, while BJGS only publishes articles in English language, other languages used in the Global South (e.g. Amharic, Bahasa Indonesia, Burmese, Farsi, French, Hindi, Sinhala and Spanish, etc.) are encouraged to be used for research and illustrations. A non-English abstract may be added after the English one.

BJGS's encouragement to make the paper abstracts available in an additional language of the authors choice and encouragement to present data in original named-languages is a much-needed democratic move. Authors of the 12 papers in this special issue collection have contributed papers in English and abstracts in both English and one other named-language. ${ }^{14}$ Many have also submitted illustrations in named-languages aligned to their data sources. Here we can highlight the need for ethical considerations in the research enterprise in general to go beyond mandatory research ethics and rules. These need to be expanded to include the languaging repertoires of scholars, not least in how fieldwork has been organized, primary data generation has been handled, etc. This is a welcome opening in the mainstream publishing landscape and one that can easily constitute a new norm for many journals, not least languagefocused journals. Contemporary digital academic existence also potentially enables making not only abstracts but entire papers available in multiple named-languages. Given other enablements that contemporary digitalization opens up for, presenting papers in multiple named-languages (rather than in specific Englishes) needs to be considered as part of issues of access and the democratization of academic publishing in contemporary times.

Thus, walking-the-talk has also implied a specific gaze on the written languaging of the papers in this double special issue. During the curation/editing work, I have met different types of challenges. I take up some here in an effort

14 Some authors have made the choice to present in a non-standard variety of the other language they have chosen. 
to contribute to a dialogue on troubling contemporary taken-for-grantedness in academic publishing. A central issue regarding written languaging is that it draws attention to stringent rules of correctness (that nevertheless shift across time). ${ }^{15}$ Given the many Englishes that are recognized, for instance, in the field of World Englishes, including my word-program on which I write, I found no analytically compelling reason to invite the authors to language checking procedures for absolute correctness (whatever that could be in the 21st century). Despite the growth of the academic domain of World Englishes, what sense can we make of BJGs's instructions to authors to use either British or American English in their writing? This instruction is supportive and beneficial for the reviewer's work and the editors work of identifying reviewers who are experienced in working within the framings of these hegemonic Englishes in their review work. I aligned with the reviewer's feedback and my final editorial work with the aim to support the communicative valence of each paper.

If a global presence of narratives on the theme of Languaging, Diversity and Democracy. Contemporary issues of participation and ways-of-being is of consequence to this double special issues agenda, then - following recent discussions related to transmethodology and post-methods (Khawaja \& Kousholt 2021) - one can ask what types of Englishes can we experiment with? Are only "named" World Englishes allowed to flourish in a scenario where different Englishes are recognized (in the scholarship and our word-programs)? Furthermore, with regards to writing styles and genres, if each paper in this collection of communicating pieces does not fulfill all criteria of mainstream straight-jacket academic papers, then perhaps that is something to celebrate. Perhaps like Lewis and Baderoon (2021) and others who experiment with academic writing, such a collection constitutes a non-hegemonically framed global democratic experimentation. Following Law (2004), I saw merit in asking whether living with pluralistic alternative ways of Englishing and writing styles constitutes a mess, "then would something less messy make a mess" of what communication is.

A caveat relates however to the fact that expectations of publishing in various types of English (or French or Spanish or German, etc. i.e., former colonial languages) are entangled with Euro-American-centric epistemologies, theories, and methodologies into which scholars from global-South spaces have

15 This issue is relevant to all human languaging that is monitored in some respect. Furthermore, analytically, languaging repertoires are multimodally constituted. Thus, written, oral, signed, embodiment, deployment of tangible and symbolic resources, etc. are all dimensions of human meaning-making and communication. For present purposes, I focus on written languaging. 
been socialized into (Bagga-Gupta \& Carneiro 2021; see also Carneiro \& Silva 2020). A wariness regarding the socialization trajectories of scholars everywhere, including their mobilities, highlights the complexities that need to be treaded carefully if we are to go beyond locating scholars' bodies permanently in the north or south, east or west, or any specific place. I can illustrate some challenges related to the issues I have touched upon by reflecting momentarily on the situation of my colleagues in Sweden who grow up with English as an important secondary language in school and higher education, who meet English in media spaces, and who do not always find it easy to write in English.

How can we understand the fact that many Swedish communicating colleagues in Sweden find it cumbersome to write English texts despite English being the first extra mandatory language that they study in schools (for at least nine of their 12 years of schooling)? What sense do colleagues born into Swedish spaces and who work with issues related to multilingualism and the plethora of concepts related to multilingualism ${ }^{16}$ make of their own English writing capacities? And what ideas regarding Swedish language teaching and instruction do they hold scared when it comes to children and adults who are multilingual - refugees, immigrants, children of immigrants and minority people like Sami or deaf or Swedish Finns or Tornedalers or Roma? What cracks in conceptualizations regarding both language and language learning appear when such sticky queries are raised? The salient issue here is the need to trouble taken-for-granted linear, singular, universalizing hegemonies in contemporary academic publishing landscapes by reflecting on issues that frame both monolingualism and multilingualism in global-North settings.

Returning to the issue at hand, I decided not to pay heed to BJGs's framing for "one of the two" hegemonic Englishes in the contributions to this double special issue. The analytical questions that are important for my purposes here can be framed as follows: what constitutes monolingual writing of British or American English, when neither Great Britain nor the USA are monolingual in contemporary times (if they ever were)? Is the academic publishing sector ready to recognize multilingual British English or multilingual American English, and if so, what would languaging in those Englishes look like? Where and when does a multilingual editors' curating/editing work fall into hegemonic stances of re-writing or over-writing multilingual authors writing in different Englishes? Whose Englishes and writing conventions are privileged, and more importantly why? For present purposes, I repeatedly asked myself whether my Englishing was risking overriding an author's Englishing. While

16 For instance, bilingual/ism, mother tongue, Swedish as a Second Language, Swedish as a Second Language for the Deaf, Swedish for Immigrants, translanguaging, etc. 
these types of queries highlight my walking-the-talk stance, apart from analytically framed languaging, my final editing work (by and large) took a pragmatic low-intervention stance, keeping in mind the key need for communicating. I thereby invite you, the reader, to attempt to don a global multilingual English stance, rather than a global hegemonic stance, when you navigate the individual papers in this double special issue.

Closing Notes on Languaging in Contemporary (Academic) Existence

I wrote (most of) this introduction in the summer of 2021 after submitting the 12 stand-alone multiply reviewed studies to the BJGS editor-in chief, PakNung Wong. Working on my keyboard in July 2021 in the temporary absence of an internet connection at my home in the village of Vintrosa in Sweden, ${ }^{17}$ I was reminded of what we - at least in the geopolitical spaces of Sweden take-for-granted. Access to all corners of the planet through contemporary digitally connected lives have become the taken-for-granted norm, not least in our pandemic framed existence and not least in the sectors of higher education and research in many (not all) parts of the planet. The absence of (temporary) connectivity marked and disrupted my taken-for-granted norms regarding contemporary existence and languaging.

The work of putting together this double special issue saw its beginnings in the fall of 2018 , when the $\mathrm{CCD}$ research environment decided to bring together thinkers from across the planet - more explicitly from nation-state settings that get glossed as the global-North and the global-South or northern/western and southern/eastern/rest to discuss the theme of Multilingualism, Diversity and Democracy (MuDD) at a CCD event (see www.ju.se/ccd/mudd2019). In parallel, I was tasked by my institution to develop an international research course on the MuDD theme. This doctoral course was envisaged as an intensive international course so that students could engage with the invited scholars at the April 2019 MuDD international conference. 46 senior, junior and middle-level scholars and critical thinkers from inside and outside academics from 13 nation-states were inspirational thinkers who engaged in dialogues with one another, members of the CCD research environment and the international doctoral course during three intensive days of the Multilingualism, Diversity and Democracy themed event. In addition to presentations in English,

17 My home was in-between internet companies at that time, and we had been informed that it took 8-10 working days to shift between internet providers. 
national participants from the theater, folk high schools and regional sectors participated on the final day of the event. ${ }^{18}$ This last cross-sectorial day was enabled through interpretation between Swedish Sign Language and English. The three-day MuDD event received financial support from the Swedish Research Council and the School of Education and Communication at Jönköping University, Sweden.

The idea to curate a publication on the MuDD theme arose during the second half of 2019. The LaDD theme (Languaging, Diversity and Democracy. Contemporary issues of Participation and Ways-of-being) was conceptualized and in addition to inviting all the participants at the April 2019 MuDD event, open calls for papers were sent out to scholars through different international networks. After a first level screening of approximately 40 abstracts, authors of 18 abstracts were invited to develop their papers (a couple of these were directly elicited). 16 papers that were received were sent out for review to a team of 24 reviewers from across the planet. Each paper has gone through at least two, sometimes three rounds of reviews, each of which has been conducted by two to five reviewers. In addition, I have engaged with the papers both initially and as a final step in my editorial work. A couple of reviewers worked collaboratively to provide feedback. 12 papers made it through this reviewing process. Such a process is not the normal order of things across all academic settings across the platen. The papers then underwent one final scrutiny by the BJGS editor-in-chief.

I would like to acknowledge the fantastic work of not only the authors but also the solidarity marked supportive work of the reviewers across 2019, 2020 and 2021. Engaging with issues of global multiversal thinking has raised challenges and I am inclined to believe that in addition to my own enrichment, authors and reviewers have been strengthened through various challenges they/we have had to negotiate. The authors and reviewers' collaborations and engagement with me has contributed to making this double special issue what it has turned out to be. My journey has been rich, and I believe that this has been so for many of the travelers. You, the reader, meet the authors thinking in more depth through their individual papers.

I warmly acknowledge the reviewers in alphabetic order here and present their academic affiliations within brackets: Alessio Surian (University of Padua, Padua), Bassey Antia (University of Western Cape, Cape Town), Crina Damsa (University of Oslo, Oslo), Elisabet Nihlfors (Uppsala University, Uppsala), Giuseppe Ritella (University of Helsinki, Helsinki), Giulia Messina Dahlberg

18 See https://ju.se/download/18.1674b8f8169dc4fd7919e5b/1554463712412/Programme\%2O 10\%20April_version $\% 202 \% 20$ Apr.pdf. 
(University of Gothenburg, Gothenburg), José Sherwood (independent scholar), Karen Ann Blom (Jönköping University, Jönköping), Karl Ian Uy Cheng Chua (Ateneo de Manila University, Manila), Letizia Bonanno (University of Loughborough, Loughborough), Machunwangliu Kamei (svkм's Usha Pravin Gandhi College, Mumbai), Marleen Habond (Pontifical Catholic University of Ecuador, Quito, etc.), Nataliya Berbyuk Lindström (University of Gothenburg, Gothenburg), Om Prakash (Gautam Buddha University, Greater Noida), Peter Jones (Sheffield Hallam University, Sheffield), Radu Dinu (Jönköping University, Jönköping), Rebecka Bergman (Chalmers University of Technology, Gothenburg), Renira Gambarato (Jönköping University, Jönköping), Sara Goico (University of California, Los Angeles), Seetha Lakshmi (National Institute of Education, Singapore), Sylvi Vigmo (University of Gothenburg, Gothenburg), Susanne Mohr (Norwegian University of Science and Technology, Trondheim), Vanajah Shiva (Jönköping University, Jönköping), and Ylva Lindberg (Jönköping University, Jönköping).

I would also like to acknowledge the solidarity framed collaboration with Pak-Nung Wong. Entrusting the curation of scholarship that attempts to challenge the hegemonies of mainstream academic writing and publishing, and that nevertheless needs to meet what we gloss as international standards, calls for exhibiting dexterity, care, and vision. I would like to recognize Pak-Nung Wong as a dialogical partner throughout this process. He recognized the task of going beyond mainstream global-North hegemonies of academic publishing, including the need to walk-the-talk, not least given the theme of this double special issue. Finally, I would like to thank the engagement of Susanne Smithberger, lecturer at the School of Education and Communication, Jönköping University, who worked closely with me in the spring of 2021 and liaised with the authors of the 12 papers in the run-up to submitting the papers to the BJGs editor-in-chief.

Contemporary digital existence, layered by our ways-of-being since March 2020 , have shaped the production of this double special issue. I have not met any of the authors or reviewers or the BJGS editor-in-chief or even Susanne Smithberger in connection with the work that has gone into curating this collection. All languaging has taken place digitally. This complex work, that has involved at least 42 scholars in various roles, has being mediated through digital tools during the ongoing pandemic. This itself illustrates some contemporary dimensions related to diversity, participation and ways-of-being in the world.

As promised at the start of this introduction, I end on a final note on the two opening phrases. A first level access to the two phrases (for those who cannot read the Devanagari skript) involves a transliteration from Devanagari to Latin: Tattv mimansa. Tat Tvam Asi. At a second level I offer some explanation in lieu 
of a translation: तत्त्व implies thatness/reality and मीमांसा critical reflection/ investigation. तत् त्वम् असि is a gloss that points to the ontological-epistemological basis of who I/you/we are. Going beyond mainstream universal linear thinking, तत्त्व मीमांसा and तत् त्वम् असि offer layered multiversal openings that call for unlearning to learn about what it means to be human in contemporary times. They offer layered multiversal openings that call for unlearning to learn about what academic writing and publishing can mean in contemporary times. Instead of cementing a niche area of scholarship, it is my hope that the 12 papers in this collection offer openings for a multitude of critical reflections both from global scholars and on global issues related to languaging, diversity and democracy, through an interest in participation and ways-of-being.

\section{References}

Bagga-Gupta, Sangeeta. (2021). On Naming Traditions. Losing sight of communicative and democratic agendas when language is loose inside and outside institutionalscapes. In Kaiper, A., Mokwena, L. \& Makoni, S. (Eds.). Handbook of Language and Southern Theory. New York: Routledge.

Bagga-Gupta, Sangeeta \& Carneiro, Alan. (2021). Commentary: Nodal frontlines and multisidedness. Contemporary multilingual scholarship and beyond. Special issue: Advances in the studies of semiotic repertoires. International Journal of Multilingualism. 18(2): 320-335.

Bagga-Gupta, Sangeeta. \& Messina Dahlberg, Giulia. (2021). On studying peoples' participation across contemporary timespaces: Disentangling analytical engagement. Outlines. Critical Practice Studies. Special Issue: Transmethodology: Research Beyond Proceduralism. 22(1): 49-88.

Carneiro, Alan \& Silva, Daniel. (2020). From anthropophagy to the anthropocene: On the challenges of doing research in language and society in Brazil and the global south. (Tilburg Paper in Culture Studies No. 246). Tilburg: Tilburg University.

Collyer, Fran. (2016) Global Patterns in the Publishing of Academic Knowledge: Global North, Global South. Current Sociology. 66(1):56-73.

Connell, Raewyn. (2018). Decolonizing sociology. Contemporary Sociology - A Journal of Reviews, 47(4): 399-407.

Connell, Raewyn. (2019). The Good University. What universities actually do and why it's time for radical change. Croydon: Zed.

Deumert, Ana. \& Makoni, Sinfree. (Eds.). (forthcoming). From Southern Theory to Decolonizing Sociolinguistics - Voices, Questions and Alternatives. Cleveland: Multilingual Matters.

Finnegan, Ruth. (2015). Where is Language? An anthropologist's questions on language, literature and performance. London: Bloomsbury. 
Harris, Roy. (2002). The role of the language myth in the western cultural tradition. In Harris, Roy (Ed.) The language myth in western culture. Pp 1-24. New York: Routledge. Harris, Roy. (2009). Rationality and the literate mind. New York: Routledge.

Heller, Monica, \& McElhinny, Bonnie. (2017). Language, capitalism, colonialism: Toward a critical history. Toronto: University of Toronto Press.

Joseph, John. (2021). Preface. In Makoni, Sinfree, Verity, Deryn \& Kaiper-Marquez, Anna (Eds.) Integrational Linguistics and Philosophy of Language in the Global South. Routledge Advances in Communication and Linguistic Theory. Pp xiii-xv. New York: Routledge.

Khawaja, Iram \& Kousholt, Dorte (2021). Editorial - Transmethodology: Creating spaces for transgressive and transformative inquiry. Outlines - Critical Practice Studies. 22(1): 1-21.

Law, John. (2004). After Method: Mess in social science research. London: Routledge.

Lewis, Desiree \& Baderoon, Gabeba (2021). Introduction. In Desiree Lewis \& Gabeba Baderoon (Eds). Surfacing. On Being Black and Feminist in South Africa. 1-14. Johannesburg: Wits University Press.

Lincoln, Yvonna and Guba, Egon. Naturalistic Inquiry. Beverly Hills: Sage Publications. 1985 .

Machart, Regis, Clark, Julie Byrd \& Dervin, Fred, (2014). Perceived differences, exhibited, diversity and overlooked individualities. The International Journal of Education for Diversities. 3: i-vi.

May, Stephen. (2014). Introducing the 'multilingual turn'. In Stephan May (Ed.) The multilingual turn. Implications for SLA, TESOL and Bilingual Education. Pp 1-6. New York: Routledge.

Mufwene, Salikoko. (2020). Decolonial linguistics as paradigm shift: A commentary. In Deumert, Ana, Storch, Anne \& Sheperd, Nick. (Eds.). Colonial and Decolonial Linguistics: Knowledges and Epistemes. Pp. 289-300. Oxford: Oxford University Press.

Ndhlovu, Finex \& Makalela, Leketi (2021). Decolonising Multilingualism in Africa. Recentering silenced voices from the Global South. Bristol: Multilingual Matters.

Pavlenko, Agneta. (2019). Superdiversity and why it isn't. Reflections on terminological innovations and academic branding. In Schmenk, Barbara, Breidbach, Stephan \& Küster, Lutz (Eds.). Sloganizations in language education discourse. Conceptual thinking in the age of academic marketization. Pp. 142-168. Bristol: Multilingual Matters.

Porsanger, Jelena \& Seurujärvi-Kari, Irja (2021). Sámi dutkama máttut:The Forerunners of Sámi Methodological Thinking. In Virtanen, Pirjo Kristiina, Keskitalo, Pigga \& Olsen, Torjer (Eds.). Indigenous Research Methodologies in Sámi and Global Contexts. (33-64). Leiden: Brill Sense.

Rodríguez, Clelia. (2018). Decolonizing academia: Poverty, oppression and pain. Black Point, Nova Scotia: Fernwood Publishing. 
Santos, Boaventura de Sousa. (2018). The end of the cognitive empire: The coming of age of epistemologies of the south. Durham: Duke University Press.

Schwartz, Peter and Ogilvy, James. The emergent paradigm: Changing patterns of thought and belief. Analytical Report 7, Values and Lifestyles Program. Menlo Park, CA: SRI International.

Savransky, Martin. (2017). A decolonial imagination: Sociology, Anthropology and the politics of reality. Sociology, 51(1): 11-26.

Svallfors, Stefan. (2020). The inner world of research. On academic labor. London: Anthem Press. 